\title{
REPRESENTAÇÕES DA PREMATURIDADE POR MULHERES USUÁRIAS DO SERVIÇO PÚBLICO DE SAÚDE
}

Magda Dimenstein*

RESUMO. Trata-se de um relato de uma experiência profissional ocorrida no serviço de obstetrícia e ginecologia de uma maternidade pública do Rio de Janeiro. Objetiva-se elucidar os significados da prematuridade construídos por mães de bebês nascidos prematuramente e internados em berçários de alto e médio riscos. Os dados aqui discutidos foram obtidos através de diferentes procedimentos: observação participante na enfermaria e berçários; entrevista semi-estruturada com as mães; grupo de discussão realizado semanalmente com usuárias e equipe de saúde, atendimento individual com as mães e familiares dos bebês. Em linhas gerais, pode-se dizer que nesse contexto específico, são muito freqüentes entraves na comunicação entre a equipe profissional, mães e familiares, devido aos diferentes estilos discursivos, bem como à diversidade de crenças e valores em relação à prematuridade. Esse quadro deriva para uma baixa contratualidade e adesão das mães ao tratamento e prescrições médicas, o que tem implicações sérias no que diz respeito aos cuidados com os bebês. O psicólogo, como parte da equipe de saúde, pode desempenhar uma função importante enquanto mediador e potencializador de relações mais humanizadas dentro dos serviços de saúde, impactando na qualidade da atenção prestada.

Palavras-chaves: prematuridade, equipe de saúde, comunicação médico-paciente.

\section{REPRESENTATIONS OF PREMATURITY ON FEMALE USERS OF PUBLIC HEALTH SERVICES}

ABSTRACT. This is a report on a professional experience in obstetrics and gynecological services at a public maternity in Rio de Janeiro. The purpose is to elucidate the meanings of prematurity from the point of view of mothers of babies prematurely born and interned on high and medium risk nurseries. Data here discussed have obtained through different procedures: participative observation in

* Doutora em Saúde Mental, professora do Departamento de Psicologia da Universidade Federal do Rio Grande do Norte (UFRN).

Endereço para correspondência: UFRN, CCHLA, Departamento de Psicologia, sl. 607, Campus Universitário, CEP 50078-970, Natal-RN. E-mail: magdad@uol.com.br

\begin{tabular}{|l|l|l|l|l|l|}
\hline Psicologia em Estudo & DP/CCH/UEM & v. 5 & n. 2 & p. 33-47 & 2000 \\
\hline
\end{tabular}


infirmary and nursery services; half-structured interviews with mothers; weekly discussion groups with users and health team, individual attendance on mothers and babies' relatives. In general, we can say that, within this specific context, there are frequent hindrances in communication between health team, mothers and relatives, due to different speech styles as well as the different beliefs and values in relation to prematurity. That scene leads to low agreement and little mothers' adhesion to treatment and medical prescriptions, which has serious implications on babies' cares. The psychologist, as part of the health team, may play an important role as intercessor and stimulator of more humanized relations inside health services having, this way, an impact on quality of given attendance.

Key words: prematurity, health team, doctor-patient communication.

Esse trabalho é resultado de uma experiência de seis meses durante o ano de 1995 no serviço de Obstetrícia e Neonatologia do Hospital Universitário Pedro Ernesto (HUPE) da Faculdade de Ciências Médicas da Universidade Estadual do Rio de Janeiro (UERJ), como parte das atividades práticas do curso de Especialização em Psicologia Médica. O estudo teve como ponto de partida o interesse em investigar o discurso de mulheres internadas na enfermaria de Obstetrícia sobre a experiência de terem filhos nascidos de parto prematuro; em encontrar o significado atribuído a essa vivência e, principalmente, em conhecer sua percepção acerca de seus bebês, assim como o modelo de mãe que elaboram como sendo o mais adequado em termos de cuidados e de expectativas para a criação dos filhos prematuros. Além disso, objetivou-se conhecer como se estabelecia a relação médico-paciente nesse contexto, focalizando a comunicação entre as partes, para identificar as dificuldades que se apresentavam em nível comunicativo e, conseqüentemente, os impasses vividos na interação cotidiana.

É preciso deixar claro que a experiência a ser relatada aqui diz respeito somente ao trabalho realizado com as mães e a equipe de saúde, e não àquele realizado diretamente com os bebês. Isso implica dizer que não se trata de um estudo voltado para a discussão a respeito da prematuridade em si, da própria definição do conceito de risco; de como a Psicologia vem tratado esse tema; de que impactos a prematuridade tem sobre o desenvolvimento infantil; de que tipo de intervenções têm sido preconizadas e/ou estudadas no atendimento a crianças prematuras. Essa é uma tarefa futura. Trata-se, portanto, de um estudo acerca das 
representações sociais de mães em torno da prematuridade e suas implicações na dinâmica de uma enfermaria pública.

\section{DESENVOLVIMENTO DO ESTUDO}

Como referido anteriormente, o alvo deste trabalho foi a enfermaria de Obstetrícia e Neonatologia do HUPE/UERJ, a qual possui uma especificidade que a faz diferente das outras maternidades. Em primeiro lugar, está inserida dentro de um hospital geral, ou seja, ela funciona nos moldes e segue a mesma rotina de qualquer enfermaria de um hospital, distinguindo-se das maternidades comuns, que têm uma flexibilidade maior nos horários de visita e uma estrutura física que dá mais privacidade às mães e aos bebês. Em segundo lugar, este serviço é dirigido exclusivamente às gestantes de alto risco, isto é, mulheres cuja gravidez é ou foi considerada de risco para si próprias e/ou para seus filhos, em função da existência de alguma patologia que afetasse diretamente a gestação - como por exemplo as doenças cardiovasculares ou simplesmente por entrarem em trabalho de parto prematuro, necessitando, assim, de cuidados especiais para si e para seu bebê. Por fim, é uma enfermaria de um hospital-escola. Tais características não podem ser desprezadas, pois impõem um ritmo especial ao funcionamento da enfermaria, desde a grande circulação de acadêmicos, residentes e profissionais de todas as áreas até à existência de rotinas mais rígidas do que as existentes em uma maternidade comum.

A equipe de saúde era composta por médicos obstetras e pediatras, residentes e acadêmicos de medicina, enfermeiras e auxiliares de enfermagem, nutricionista e psicóloga. Havia um revezamento da equipe nos três turnos (com exceção da psicóloga), além da rotatividade em função do sistema de plantão. Dessa forma, a equipe se re-arranjava a cada dia, bem como o número de acadêmicos e residentes mudava de acordo com as regras de seus preceptores.

Os dados aqui discutidos foram colhidos durante os seis primeiros meses de 1995, através de diferentes procedimentos: observação participante na enfermaria e em berçários, com o objetivo de conhecer a dinâmica destes espaços, verificação de como se estabeleciam as relações interprofissionais e destes com as usuárias; entrevista semiestruturada com as mães cujos bebês encontravam-se no berçário patológico BP/UTI neonatal, assim como no berçário intermediário 
(BI)/de recuperação. Esta foi aplicada individualmente, na maioria das vezes no leito das mulheres, no turno da tarde - freqüentemente mais tranqüilo do que o da manhã - horário em que se dava a visita médica.

Outro recurso utilizado foi a criação de um grupo de discussão, realizado semanalmente com usuárias e a equipe de saúde, cujo objetivo era promover uma melhor integração entre as partes, desenvolver práticas de saúde mais humanizadas e contextualizadas. Tais ocasiões se configuraram como momentos frutíferos para a observação da relação médico-paciente, e do funcionamento do grupo de mães, especificamente.

Por fim, alguns dados foram colhidos no momento do atendimento individual feito junto às mães dos bebês, atividade realizada diariamente nas dependências do hospital. $\mathrm{O}$ contato com as mães foi mantido primeiramente no grupo de discussão. Após esse primeiro contato, e de posse dos nomes daquelas mulheres que se encaixavam no perfil da pesquisa (mães de bebês prematuros, ou seja, aqueles que nascem com até 37 semanas de gestação), tentou-se um contato individual com cada uma delas, no qual era esclarecido o objetivo da entrevista e se perguntava se elas gostariam de participar. Não houve muita resistência por parte delas, pois, uma vez que o entrevistador era membro da equipe de saúde, era parte do cotidiano da enfermaria, essa atividade foi encarada como mais uma das funções da Psicologia dentro da instituição. Por esse mesmo motivo decidiu-se não gravar as entrevistas, a fim de evitar qualquer tipo de mal-estar entre as mães, já que esse era um procedimento que contrastava bastante com o que era normalmente feito. Assim, considerou-se mais apropriado fazer anotações à medida que fosse respondendo às questões propostas.

No total, foram realizadas 14 entrevistas, com mulheres internadas entre os meses de maio e julho. Como forma de garantir a diferenciação e o anonimato das citações, as entrevistas foram numeradas de acordo com a ordem de sua realização. Assim $E_{1}$ foi a primeira entrevistada e $\mathrm{E}_{14}$ a última. Passemos, então, à apresentação dos principais dados referentes às pacientes, à gravidez e aos bebês.

\section{RESULTADOS}

\section{Perfil das mulheres entrevistadas}

- Idade: têm em média 26 anos. 
- Estado civil: $64 \%$ são casadas e $36 \%$ solteiras.

- Educação formal: $43 \%$ não concluíram o primeiro grau, 42\% têm o segundo grau incompleto e $15 \%$ possuem curso superior incompleto.

- Atividade profissional: $72 \%$ são donas de casa e as restantes são costureira, auxiliar de enfermagem, datilógrafa e professora primária.

- Renda familiar: $28 \%$ têm renda familiar de um a três salários mínimos e 72\% mais de três salários mínimos.

- Planejamento da gravidez: 50\% não planejaram a última gravidez.

- Tempo de acompanhamento pré-natal: O tempo médio de assistência pré-natal foi de cinco meses.

- Natureza das instituições de saúde onde fizeram pré-natal: apenas uma paciente fez acompanhamento pré-natal em clínica particular; o restante, em instituições públicas.

- Número de gestações: 43\% são nulíparas; 57\% são multíparas.

- Número de filhos: $72 \%$ só têm esse filho recém-nascido e já perderam outros bebês em função de gestações de alto risco.

- Tipo de parto: Nove mulheres fizeram cesariana e cinco, parto normal na última gestação.

- Diagnósticos mais freqüentes: eclâmpsia, doença vascular hipertensiva crônica, lupus, oligoidrâmnio, amniorrexe prematura, diabetes e causa desconhecida.

\section{Perfil dos bebês internados}

- Quanto ao número de semanas ao nascer: $40 \%$ de 32 a 35 semanas; $33,3 \%$ de 28 a 31 semanas e $26,7 \%$ de 36 a 37 semanas;

- Quanto ao peso ao nascer: $33,3 \%$ de 1,5 a $2,0 \mathrm{~kg} ; 26,7 \%$ de 1 a $1,5 \mathrm{~kg}$; $26,7 \%$ de 2,0 a $2,5 \mathrm{~kg}$ e $13,3 \%$ de 2,5 a $3,0 \mathrm{~kg}$.

\section{Determinantes da prematuridade segundo as mães}

De acordo com as entrevistas, das 14 mulheres apenas 4 consideraram a prematuridade uma decorrência de problemas restritos à esfera física, havendo assim uma similaridade com o diagnóstico médico. O restante das pacientes (10) atribuiu ao nascimento prematuro de seus filhos mais a outros fatores, relacionados a uma situação de stress 
psicológico, ocasionado por conflitos familiares e/ou no trabalho, por dificuldades de assistência médica, por mudança de cidade e especialmente por uma ansiedade frente ao parto, do que propriamente a problemas de ordem física. Estes, quando aconteciam, eram entendidos como oriundos ou agravados por problemas de ordem emocional ou social.

Eu atribuo essa subida de pressão à minha ansiedade, minha preocupação com o parto, com o medo de ficar procurando hospital e não encontrar vaga, de não ter socorro na hora que eu precisar $\left(\mathrm{E}_{3}\right)$.

Não sei porque o bebê veio antes do tempo. Acho que fiquei muito ansiosa pra que o bebê viesse logo. Eu dizia sempre "vem logo bebê". Tinha muita curiosidade de ver ele. Eu sempre quis ter um filho. Antes do bebê nascer eu tive um sonho: sonhava que eu dizia pro meu marido: meu nenê nasceu! e ele dizia: como, se ainda não tá na hora? $\left(\mathrm{E}_{2}\right)$.

\section{Diferença entre bebês normais e prematuros}

Das 14 entrevistadas, 11 consideraram que o bebê prematuro é diferente do normal, não só em função do baixo peso, mas principalmente porque ele requer muito mais cuidados do que aquele que nasce a termo. Segundo as mães, eles são mais frágeis, adoecem mais rápido e demoram mais tempo para se recuperar do que os bebês de 9 meses. Além disso, existe a idéia de que eles não reagem direito aos tratamentos e quando adoecem ficam mais graves do que os normais. Ou seja, eles precisam muito mais dos cuidados maternos pelo fato de serem prematuros.

Algumas mães tinham a preocupação com a futura normalidade de seus filhos, não só na esfera física mas sobretudo em termos da sua capacidade intelectual, como se o fato de nascerem prematuramente tivesse selado o seu destino de "incapazes" para a vida. Isso de alguma forma vinha concomitante a uma sensação de fracasso vivida pela mãe, como se ela não tivesse sido capaz de gerar um filho saudável.

Eu acho que os prematuros são mais fraquinhos $e$ precisam de mais cuidados especiais porque nasceram 
antes do tempo, aí não tavam preparados, precisam de ajuda. Ele não nasceu pronto como o bebê normal $\left(\mathrm{E}_{6}\right)$.

\section{Impacto da equipe de saúde e de práticas hospitalares sobre as mães}

Todas as entrevistadas disseram ser esse o período mais crítico de suas vidas. A tensão com a hospitalização era comum a todas: dificuldade de relacionamento com a equipe de saúde, dificuldade para obter e entender as informações dadas pelos técnicos, de adaptar-se à rotina do hospital e de aceitar o lento processo de recuperação de seus filhos. A relação das pacientes com a equipe era um fator de stress e, juntamente com a situação do bebê, tornava-se algo que interferia negativamente em sua estabilidade emocional. Algumas mulheres ficavam ansiosas pelo fato de não poderem pegar os seus bebês, acariciá-los e amamentá-los, tal como tinham planejado durante a gravidez. Outras sofriam ao verem seus filhos cheios de agulhas, fios e aparelhos.Imaginavam que eles estavam sofrendo e não podiam fazer nada.

Outro fator que trazia muita ansiedade para as mulheres era a ausência de casa por tempo indeterminado, já que muitas delas nunca tinham se afastado de casa, deixando assim os outros filhos ao encargo da família. Essa situação de isolamento familiar - pois nem todos os maridos podiam vir visitá-las diariamente - imprimia uma sensação de desproteção, deixando-as bastante vulneráveis.

É muito angustiante ficar no hospital, tudo deixa você neurótica. Hoje o bebê não deixou resíduo, de noite já deixou. Esse vai e volta acaba com os nervos. Se não fosse tão alto pensava até em me jogar pela janela. Esses 15 dias estão durando uma eternidade. A expectativa deixa você maluquinha $\left(\mathrm{E}_{7}\right)$.

Eu já tô louca para ir embora. Já tô tendo uma estafa: não durmo direito, não me alimento direito, em casa durmo muito melhor, a mente fica mais arejada, aqui a gente escuta muito grito, em casa a mente fica no lugar. Aqui é impossível descansar $\left(\mathrm{E}_{8}\right)$.

Eu tô muito ansiosa para ir embora, mas não quero ir sem o meu filho. O meu primeiro bebê também ficou 
internado e eu não aguentei ficar esperando. Deixei ele no hospital mas ele morreu. Fiquei me sentindo muito culpada com isso e não quero que aconteça de novo. Acho que se eu ficar vou ajudar ele se recuperar $\left(\mathrm{E}_{14}\right)$

Uma questão interessante que foi percebida é que essas mulheres encontram forças para agüentar a espera de seus bebês na luta que essas crianças travam no dia-a-dia, pela própria sobrevivência.

Tô muito ansiosa, quero sentir o corpo a corpo, pois só aí vou sentir que ela é minha mesmo. Quero ela junto de mim. O esforço dela me estimula a esperar, a ter paciência. Eu não posso acabar o esforço que ela teve para sobreviver, eu tenho que dar continuidade a isso. Ela tá me ajudando muito mais do que eu a ela $\left(\mathrm{E}_{13}\right)$.

Diferentemente do que se possa imaginar, grande parte das mulheres consideram-se aptas para cuidar dos seus bebês logo que saírem do hospital. Muitas já tiveram experiência com irmãos menores, sobrinhos ou mesmo os próprios filhos, de forma que nem todas acham que vão precisar de ajuda. Entretanto, há aquelas que ao saírem da maternidade pretendem ir direto para a casa de seus pais ou da sogra, com pretensão de ficar alguns meses, principalmente as mães primíparas que consideram o apoio da família fundamental.

\section{CONSIDERAÇÕES SOBRE O DISCURSO MÉDICO E A PERCEPÇÃO DAS MÃES EM RELAÇÃO À PREMATURIDADE}

Após o período de seis meses dentro da enfermaria, com base nas observações, leitura dos prontuários e discussões em grupo, foi possível perceber que o discurso das mulheres sobre a prematuridade difere substancialmente do discurso médico, no sentido de que esse último é construído predominantemente sobre as bases biológicas da prematuridade, ou seja, há naturalização desse acontecimento, ao passo que as mulheres lançam mão de outros determinantes de ordem psicológica e social, tendo assim uma visão mais holística e complexa da experiência de terem filhos prematuros.

Essa diferença, no nosso entender, deriva para uma baixa contratualidade na relação médico-paciente - na medida em que as 
mulheres não compartilham do diagnóstico elaborado pelo médico -, indicando assim o estabelecimento de uma relação de natureza assimétrica e verticalizada, que se materializa em termos de prescrições e informações do lado do médico, e de seu mero "consumo" por parte das pacientes.

Isto, por sua vez, está diretamente relacionado à racionalidade médico-científica moderna, à concepção mecanicista do organismo humano, ao conceito biomédico de doença, de acordo com o qual, segundo Capra (1982), as doenças são entidades bem definidas e têm raízes causais únicas, lineares. Ou seja, relaciona-se com a própria forma de constituição do discurso médico, na medida em que versa sobre doenças, lesões, sintomas e sinais que devem ser buscados no interior do organismo e corrigidos por algum tipo de intervenção concreta, seja medicamentos, cirurgia ou radiação. Essa atitude deriva da visão cartesiana do homem-máquina, na qual a intervenção médica é efetuada com o objetivo de corrigir um defeito (sintoma,doença) que está causando algum desconforto ao paciente. Nesse sentido, sofrimento, subjetividade, vivências, emoções, etc, são questões historicamente excluídas desse discurso, já que escapam aos preceitos da objetividade e da cientificidade almejadas pela medicina, como estratégia de legitimação social.

Segundo Camargo Jr. (1992),

A “ciência médica” permanece como norma institucional (e como modelo ideal), e tudo que a contraria é afastado, com apoio na ordem jurídica, inclusive. Assim, tudo o que se refere à subjetividade, ao imaginário (por exemplo), é posto de lado como não científico, sendo objeto de uma "farmacologização" tão maciça quanto cega - sempre em nome da ciência (p.207).

Assim, continua o autor,

a ciência médica repete Procusto no seu afã de enquadrar, demarcar, disciplinar, normatizar. $E$ ai daqueles que não respeitam a norma correta de adoecer! São os funcionais, os que não têm nada, os polissintomáticos, os pitiáticos - a eles, o castigo (p.208). 
Dessa forma, dentro do enfoque biomédico, somente o profissional médico tem autoridade e conhecimento a respeito da saúde e da doença do indivíduo, conhecimento este considerado racional, objetivo, científico. A relação do médico se estabelece, pois, com a doença e não com a pessoa portadora de alguma doença, cujo sofrimento é destituído de qualquer valor, tornado irrelevante. Isso é o que leva Clavreul (1983) a chamar atenção para o fato de que falar da relação médico-paciente é praticamente falar de um mito, já que na sua opinião essa relação não existe. Do seu ponto de vista, a existência de uma corporação médica, de um vocabulário técnico especializado, assim como de uma legião de doentes, nada disso é suficiente para fundar ou legitimar a relação médico-paciente, pois o que se dá, de fato, é o apagamento da subjetividade tanto de um quanto de outro.

À medicina só interessa a doença, daí o distanciamento do médico em relação ao paciente. De um lado, o médico se anula enquanto sujeito, perante a exigência de objetividade científica do diagnóstico, dos exames, dos tratamentos e de todas as decisões terapêuticas adotadas por ele. Do outro lado, o paciente, identificado à doença, perde sua singularidade e sua capacidade de falar enquanto sujeito. Além de todo esse afã científico de exatidão do saber médico, que serve de máscara, como nos aponta Clavreul (op.cit), e que ofusca a impotência desse saber diante do sofrimento humano, a medicina descarta tudo o que há de singular, de particular em cada forma de adoecer, e se devota somente a encontrar o que há de semelhante em termos de sintomatologia, a fim de que possa catalogar, construir categorias nosográficas, nas quais possa encaixar os doentes e assim universalizar seu saber à todas as pessoas dos mais diversos lugares.

A doença, concebida a partir de pressupostos universalistasessencialistas, pertencente exclusivamente à ordem do biológico, é totalmente naturalizada no corpo, não restando espaço para pensá-la em termos dos determinantes culturais e das particularidades de cada indivíduo, como sua classe social e seus sistemas de crenças e valores. Em outras palavras, são feitos diagnósticos, são aplicadas técnicas médicas sem a preocupação de se contextualizar os pacientes, sem levar em consideração que muito do fracasso observado em termos de condutas médicas é fruto da descontextualização e do "esquecimento" das especificidades do paciente em função do seu contexto sociocultural.

Essa problemática não é alheia, de forma alguma, ao campo da Psicologia. É comum o psicólogo deparar-se em sua prática cotidiana, 
nos serviços públicos, com resultados aquém dos pretendidos. Nesta situação, geralmente o profissional atribui seu insucesso à falta de capacidade dos usuários em compreender a tarefa terapêutica, negando, por exemplo, os problemas advindos das diferenças culturais de subjetividade entre profissionais e pacientes. Ou seja, a abordagem dos técnicos está baseada em pré-requisitos etnocêntricos que não contemplam a questão da diferença. Dessa forma, seus modelos de atuação e seu arsenal teórico-prático permanecem inquestionáveis quanto à sua eficácia e adequação à população do serviço público de saúde.

Não é desconhecido o fato de que predominam no campo da Psicologia enfoques segundo os quais o indivíduo é tratado como um ser abstrato e a-histórico, sem as marcações de gênero, raça, etnia, desvinculado de seu contexto social, como se todos os membros da espécie humana fossem iguais em qualquer época e lugar. A Psicologia é um campo marcado por teorias essencialistas e universalistas em relação ao modelo de mulher, família, sexualidade e a certas representações, como as de sofrimento psíquico, subjetividade, corpo, etc. Possuímos também uma determinada idéia - tida como universal - do que seja saúde e doença, de suas causas e possibilidades de tratamento e cura, a qual nem sempre é compartilhada pelos nossos pacientes.

Em outra ocasião (Dimenstein,1997) ressaltamos a diversidade e o conflito entre os significados de maternidade construídos por usuárias de serviços públicos de saúde e pelas equipes profissionais, e a crença de que isto termina funcionando como um impedimento à proposta de assistência integral à saúde da mulher. Neste contexto, partimos da concepção de que a maternidade é uma construção social e não uma predisposição natural da mulher, uma essência feminina que independe de tempo e lugar, tal como é preconizada no discurso médicopsicológico. Dessa forma, como qualquer outra questão humana, é indissociável do contexto, dos códigos, dos valores e das crenças; enfim, das representações de uma sociedade. Acreditamos que em relação à prematuridade, a orientação naturalizadora predominante no discurso médico seja, entre as formas de essencialismo, uma doa mais difíceis de serem erradicadas, pois encontra, na maioria das vezes, um aparente fundamento no corpo da mulher, uma “causa” orgânica que justifica todo o resto.

Este estudo vem, de certa forma, corroborar tal perspectiva, uma vez que foi possível perceber que as mulheres entrevistadas têm uma concepção muito mais ampliada dos processos que ocorrem no seu corpo, 
desafiando assim a naturalidade da prematuridade dos bebês, e trazendo à tona elementos que escapam ao determinismo biológico presente no discurso da equipe de saúde, especialmente entre médicos e estudantes. Além disso, percebemos que o nascimento prematuro de um filho configura-se como uma situação de crise psicológica para a mulher, primeiro pela interrupção repentina da gravidez, pela possibilidade concreta de morte de seu filho, pela impossibilidade de ter contato físico com ele, seguidos dos problemas oriundos da sua permanência compulsória por muito tempo num ambiente associado a dor, sofrimento e morte.

Muitas entrevistadas disseram estar vivendo um completo esgotamento físico e psicológico, o que as leva a desconsiderar a possibilidade de virem a engravidar novamente. Essa situação de crise também é agravada pela idéia de que seus filhos terão mais dificuldades, tanto físicas quanto psicológicas, para enfrentar a vida futura. A percepção destes problemas levou a equipe de saúde a organizar o grupo de discussão com mães e profissionais, com o objetivo de abrir um espaço dentro da enfermaria no qual as mulheres pudessem expressar seus pensamentos e sentimentos sobre o bebê, sobre a equipe e o serviço prestado. Nesse sentido, o grupo foi muito produtivo, não só na condução de questões práticas, mas principalmente pela tentativa de abordar aspectos psicológicos, junto a estas mulheres, ligados à sua experiência de terem tido um bebê prematuro.

O interessante foi que elas próprias começaram a desenvolver uma rede de solidariedade, uma rede de apoio com capacidade de estímulo e motivação, principalmente para aquelas mães que apresentavam mais dificuldades neste percurso e que não conseguiam ir até o berçário visitar seu filho, e para aquelas cujos bebês se encontravam em situação grave. Pode-se dizer, também, que esse momento de instabilidade emocional parece ser agravado pelo fato de que o próprio funcionamento da equipe de saúde é muitas vezes iatrogênico ${ }^{1}$, gerando com isso um sentimento de desconfiança por parte das mães em relação à qualidade dos serviços prestados.

Essa questão, entretanto, só foi mencionada nas entrevistas individuais; logo, tinha um caráter sigiloso, em função do medo que sentiam de represálias e de maus tratos para com seus bebês. Trata-se,

1 Doenças iatrogênicas - do grego “iatros”, “médico”, e “gênesis”, “origem” - são doenças geradas pelo próprio processo de assistência médica. (Capra, 1982,p.141) 
pois, de um contexto que guarda características especiais, as quais se refletem na interação entre a equipe de saúde e as mulheres ali internadas, já que a morte, longe de ser apenas uma possibilidade, configura-se com freqüência no desfecho de uma parcela significativa dos bebês, o que vem por sua vez, contrariar as expectativas, tanto das mães quanto dos familiares, em relação à própria equipe de saúde. Por outro lado, a situação de internação "forçada" vivida por estas mães, à espera de seus filhos, é geradora de muita ansiedade, tanto para as mulheres, que têm que viver a rotina hospitalar, quanto para os profissionais, que têm que lidar com um tipo "diferente" de paciente, que não se encontra tão dependente dos seus cuidados. Isto gera muitos conflitos dentro das enfermarias, os quais nem sempre têm uma resolução satisfatória.

O tempo de permanência nessa enfermaria possibilitou também a observação de uma série de situações de interação entre médico e pacientes e das pacientes entre si, assim como os muitos entraves que se estabelecem diariamente e os diferentes estilos discursivos entre os atores. Deparamo-nos com diferentes crenças e valores referentes ao corpo, à vida e à morte, e principalmente em termos dos códigos utilizados para significar saúde e doença, e com as mais diferentes visões de mundo entre os médicos e as pacientes. Em termos gerais, foi possível observar que a linguagem médica, estritamente técnica, é o veículo de comunicação da equipe com seus pacientes e familiares, que, por sua vez, portadores de códigos culturais diferenciados, baseados em outras experiências e condições sociais, não compartilham dos esquemas adotados pelos profissionais.

Assim, a primeira constatação a que se chegou após este período de inserção na enfermaria é a de que há um verdadeiro descompasso em termos do relacionamento entre a equipe de saúde e as pacientes, há uma distância em nível da comunicação que se mantém porque são atores que partem de esquemas de conhecimentos totalmente distintos; enfim, esquemas contraditórios que afetam diretamente a relação, de forma que o discurso médico é vazio de sentido para as mulheres e carece de eficácia simbólica.

Segundo Figueira (1978), toda prática terapêutica só é eficaz se ela funciona enquanto sistema simbólico para o indivíduo, ou seja, se ela é capaz de lhe oferecer uma explicação, um sentido para seu sofrimento e suas vivências. Em outras palavras, é preciso haver uma certa congruência entre os sistemas simbólicos dos profissionais e os pacientes, isto é, que eles compartilhem uma visão de mundo, a crença no saber 
diagnóstico e na eficácia terapêutica, para que tenham sucesso ou eficácia simbólica

Idéias como as de causalidade e cura, por exemplo, neste contexto específico, parecem não guardar similaridade alguma entre profissionais e mães. Em decorrência disto, as mães estabelecem estratégias bastante eficazes de resistência à hegemonia do discurso médico, de forma que muitas informações e prescrições são "traduzidas" para a linguagem que é comum a todas elas, imprimindo, assim, um significado para aquilo que até então não passava de uma fala sem sentido. Entendemos essa resistência como um fator de resiliência das mães frente ao discurso institucional hegemônico; ao contrário de pensála como má vontade ou incapacidade em compreender e seguir as normas médicas e hospitalares, tal como é freqüentemente interpretada.

Muitos impasses foram desfeitos no grupo de mães, no qual os freqüentes mal-entendidos vividos entre equipe e pacientes podiam vir à tona, buscando-se uma negociação e uma compreensão dos problemas. Acreditamos que médicos e mães, na medida em que partem de referenciais distintos, de códigos culturais diferenciados, têm sua comunicação afetada, tal como foi possível observarmos em muitas situações que caracterizam baixa contratualidade e baixa adesão das usuárias às prescrições médicas. Não é raro a paciente que "esquece" o que foi recomendado pelo médico, ou burla a dieta prescrita pela nutricionista, ou joga fora o leite colhido quando era para ter guardado, sinalizando que muitas destas condutas não são postas em prática por fugirem totalmente de seu arsenal disponível.

Aliás, é com muita freqüência que vemos ocorrerem situaçõeslimites em que profissionais e mães entram em conflito em função dos diferentes esquemas perceptivos, expectativas e papéis que definem sua identidade social. Não se trata, porém, da ausência de competência por parte das mulheres para estabelecer uma comunicação eficaz com os profissionais, pois o que está em jogo é uma diversidade e uma diferença de esquemas comunicativos que é preciso reconhecer e valorizar.

O psicólogo, como parte da equipe de saúde, pode desempenhar uma função importante enquanto mediador e potencializador de relações mais humanizadas dentro dos serviços de saúde, impactando na qualidade da atenção prestada, a qual se reflete na satisfação das usuárias e na melhora dos indicadores de eficiência, tão caros atualmente ao nosso Sistema Único de Saúde (SUS). 


\section{REFERÊNCIAS BIBLIOGRÁFICAS}

Camargo, Jr. K.R.(1993). (Ir)Racionalidade médica: os paradoxos da clínica. Em Physis - Revista de Saúde Coletiva, 2(1), 203-228. IMS/UERJ: Relume Dumará

Capra, F. (1982). O Ponto de Mutação: a ciência, a sociedade e a cultura emergente. São Paulo: Cultrix.

Clavreul, J. (1983). A ordem médica: poder e impotência do discurso médico. ( J. G. Noujaim, M. A. C. Jorge, P. M. Silveira Jr., Trads.). São Paulo: Brasiliense (Originalmente publicado em 1978).

Dimenstein, M. (1997). Representações de maternidade de pacientes e terapeutas: questões para a prática da Psicologia nos serviços públicos de Teresina-PI. Em Zanella, A V. e cols. (Orgs.), Psicologia e práticas sociais (pp. 410-423). Porto Alegre: Abrapsosul.

Figueira, S.A. (1978). Notas Introdutórias ao estudo das terapêuticas I: LéviStrauss e Peter Berger. Em Figueira, S. A. (Org.), Sociedade e doença mental (pp. 47-86). Rio de Janeiro: Campus.

Recebido em 30/06/00

Revisado em 12/09/00

Aceito em 29/10/00 